Volume 3 Issue 1 (2019) Pages 137 - 145

Jurnal Obsesi : Jurnal Pendidikan Anak Usia Dini

DOI: $10.31004 /$ obsesi.v3i1.159

\title{
Pemerolehan Bahasa pada Anak Usia 3 Tahun
}

\author{
Yulia Eka Salnita ${ }^{1}$, Atmazaki ${ }^{2}$, Abdurrahman $^{3}$ \\ Pascasarjana Universitas Negeri Padang
}

\begin{abstract}
This study aims to describe the language acquisition of children aged 3 years. Language acquisition for children aged 3 years is studied at the level of phonology, syntax, and semantics. The data in this study is the speech of children after 3 years. This study uses a qualitative descriptive design. The data analysis phase in this study there are three, namely reduction, presentation, and conclusion. The results of this study indicate that at the phonological level, the research subjects have not been able to test phonemes $/ \mathrm{r} /$ and $/ \mathrm{s} /$ correctly. At the syntactic level, the subject of research has been able to test four types of sentences, namely declarative, imperative, interrogative, and exclamation sentences. Words that are controlled by children are words that are close to the child's environment. At the semantic level, all utterances of children contain denotative meaning.
\end{abstract}

Keywords: language acquisition, early childhood, phonology, syntax, semantics

\begin{abstract}
Abstrak
Penelitian ini bertujuan untuk mendeskripsikan pemerolehan bahasa anak usia 3 tahun. Pemerolehan bahasa anak usia 3 tahun ini dikaji pada tataran fonologi, sintaksis, dan semantik. Data dalam penelitian ini adalah tuturan anak usai 3 tahun. Penelitian ini menggunakan rancangan deskriptif kualitatif. Tahap analisis data dalam penelitian ini ada tiga, yaitu reduksi, penyajian, dan penarikan kesimpulan. Hasil penelitian ini menunjukkan bahwa pada tataran fonologi, subjek penelitian belum bisa mengujarkan fonem $/ \mathrm{r} / \mathrm{dan} / \mathrm{s} /$ dengan benar. Pada tataran sintaksis, subjek penelitian sudah mampu mengujarkan empat jenis kalimat, yaitu kalimat deklaratif, imperatif, interogatif, dan eksklamatif. Kata yang dikuasi anak adalah kata-kata yang dekat dengan lingkungan anak. Pada tataran semantik, semua ujaran anak mengandung makna denotatif.
\end{abstract}

Kata Kunci: Pemerolehan Bahasa; Anak Usia Dini, Fonologi; Sintaksis; Semantik

@ Jurnal Obsesi Prodi PG-PAUD FIP UPTT 2019

$\triangle$ Corresponding author :

Address : Padang

Email : salnitayulia@yahoo.co.id

ISSN 2356-1327 (Media Cetak)

ISSN 2549-8959 (Media Online) 


\section{PENDAHULUAN}

Manusia menggunakan bahasa sebagai alat berkomunikasi satu sama lain. Bahasa adalah bentuk aturan atau sistem lambang yang digunakan dalam berkomunikasi dan beradaptasi dengan lingkungannya yang dilakukan untuk bertukar gagasan, pikiran, dan emosi (Yogatama, 2011). Masa anak usia dini merupakan masa keemasan. Pada masa ini otak anak mengalami perkembangan paling cepat sepanjang hidup. Masa ini berlangsung dari usia usia nol sampai satu tahun (Fauziddin, 2018).

Pemerolehan bahasa merupakan proses yang berlangsung dalam otak anak ketika memperoleh bahasa pertama (Chaer, 2007). Senada dengan itu, menurut Dardjowidjojo (Dardjowidjojo, 2000) pemerolehan bahasa berkaitan dengan penguasaan bahasa yang dilakukan anak secara natural pada waktu belajar bahasa ibu. Pemerolehan bahasa akan terus berkembang seiring dengan bertambahnya usia anak.

Pemerolehan bahasa pertama sangat berkaitan dengan perkembangan sosial anak dan pembentukan identitas sosial. Mempelajari bahasa pertama merupakan salah satu perkembangan menyeluruh anak menjadi anggota suatu masyarakat (Yogatama, 2011). Pada masa pemerolehan bahasa anak, lebih mengarah kepada fungsi komunikasi daripada bentuk bahasa. Pemerolehan bahasa pada anak-anak mempunyai ciri-ciri berkesinambungan, merupakan suatu rangkaian kesatuan, dan dimulai dari ujaran satu kata yang sederhana hingga mencapai gabungan kata dan kalimat yang lebih rumit (Manurung, 2014). Perkembangan bahasa anak dipengaruhi oleh usia anak, kondisi lingkungan, kecerdasan anak, status sosial ekonomi keluarga, dan kondisi fisik anak (Yogatama, 2011).
Ada dua proses dalam pemerolehan bahasa pertama pada anak, yaitu proses kompetensi dan peformansi. Kompetensi adalah proses penguasaan tata bahasa yang berlangsung secara tidak disadari. Proses ini menjadi syarat untuk terjadinya proses peformansi yang terdiri dari dua proses yaitu proses pemahaman dan penerbitan kalimat yang didengar. Peformansi berkaitan dengan kemampuan memahami dan menerbitkan kalimat baru (Arsanti Meilan, 2014) (Wulandari, 2018).

Perkembangan bahasa anak merupakan kemampuan anak untuk memberikan respon terhadap suara, mengikuti perintah, dan berbicara sopan. Perkembangan bahasa berlangsung sangat cepat dan menjadi landasan dalam perkembangan selajutnya pada masa balita. (Safitri, 2017). Perkembangan bahasa pada anak usia dini melalui pemerolehan bahasa merupakan salah satu tahap penting dalam rangka transmisi bahasa agar terhindar dari kepunahan (Mayasari, 2018).

Perkembangan bahasa pada anak usia dini merupakan salah satu faktor yang mempengaruhi perkembangan kognitif anak (Pebriana, 2017). Perkembangan bahasa anak berkembang dari tingkat sederhana meuju kompleks. Hal ini dipengaruhi oleh semakin tumbuh dan berkembangnya anak seiring dengan pemahaman yang baik terhadap lingkungan. Menurut Suhartono (Pebriana, 2017), peranan bahasa bagi anak usia dini adalah sebagai sarana untuk berpikir, mendengarkan, berbicara, dan mampu untuk membaca dan menulis.

Pada usia satu tahun, anak mulai bisa mengujarkan satu kata (Dardjowidjojo, 2000). Pada usia ini anak mulai mengujarkan kata-kata yang diketahuinya dari lingkungan sekitar. Kata yang diujarkan anak pada usia ini terkadang tidak jelas dan hanya mengujarkan suku kata terakhir yang diketahuinya dari sebuah kata. Oleh karena itu, orangtua harus lebih 
memperhatikan apa yang diucapkan oleh anak mereka. Ucapan tersebut bisa saja bermakna lebih dari satu kata. Misalnya saja ketika anak mengatakan cu. Bisa saja anak mengatakan kalau dia ingin minta susu atau dia menunjukan pada orang tuanya di sana ada susu. Tugas orangtua untuk mendengarkan dan memahami apa yang diucapkan oleh anak.

Seorang anak bisa dikatakan telah menguasai kata pertamanya jika mereka dapat mengujarkan kata-kata yang telah diketahui secara luas dan kata-kata itu berhubungan dengan suatu objek atau kejadian di lingkungannya (Dardjowidjojo, 2000). Bentuk kata tersebut mungkin tidak sempurna, contohnya, 'pah' untuk 'papah', dan makna yang dia maksudkan mungkin tidak sesuai, misalnya, semua orang dia panggil 'da', akan tetapi selama anak mampu menggunakan bentuk ucapan tersebut dengan acuan tertentu, dia dianggap telah memperoleh sedikit pengetahuan kata (Steinberg, dkk, 2001).

Pada usia 2 tahun, anak sudah mampu mengucapkankan ujaran dua kata, merespon pembicaraan lawan bicara, dan masuk dalam percakapan singkat (Dardjowidjojo, 2000). Pada usia 3 tahun, anak mulai bisa melakukan percakapan lama dan bergiliran dengan lawan bicara (Yogatama, 2011). Hal ini sesuai dengan penelitian yang dilakukan oleh Darjowidjojo (Dardjowidjojo, 2000) yang meneliti perkembangan bahasa cucu perempuannya, Echa. Pada usia 2 tahun, Echa sudah mampu mengucapkan sesuatu dalam bentuk kalimat tunggal maupun majemuk. Pada usia tiga tahun, Echa sudah mampu mengucapkan kalimat deklaratif, imperatif, dan interogatif.

Anak usia 3-6 tahun telah memperoleh kosakata, yaitu kosakata dasar (kata benda, kata kerja, kata sifat, kata bilangan, kata ganti, kata yang berhubungan dengan kekerabatan, dan kata depan), kosakata turunan (imbuhan prefiks, imbuhan sufiks, imbuhan infiks, dan imbuhan konfiks), dan kosakata ulang (Nurjamiaty, 2015). Dalam rentang usia 3;0-4;0 anak juga mampu menguasai ataupun mengujarkan beberapa jenis kalimat, di antaranya adalah kalimat deklaratif/berita, kalimat imperatif/perintah, kalimat interogatif/tanya, dan kadangkadang kalimat eksklamatif/seru (Yuniarsih, 2013).

Penelian mengenai pemerolehan bahasa anak usia 3 tahun sudah pernah diteliti sebelumnya. Penelitian yang dilakukan Nursalam dan Nurhikmah (Nursalam \& Nurhikmah, 2018) menunjukan bahwa anak usia 3,6 tahun sudah mampu menuturkan empat jenis kalimat, yaitu kalimat interogratif, deklaratif, imperatif, dan interjeksi. Subjek penelitian belum mampu mengucapkan kalimat secara sempurna karena unsur sintaksisnya belum lengkap dan kalimatkalimat yang diucapkan masih terpengaruh oleh bahasa ibu. Penelitian lain yang dilakukan oleh Mushaitir (Mushaitir, 2016) menunjukkan bahwa anak usia 4-6 tahun sudah mampu menggunakan kalimat tunggal dengan klausa lengkap maupun tidak lengkap dan memiliki struktur runtut dan inversi. Selain itu, anak usia 4-6 tahun sudah mampu menggunakan kalimat majemuk koordinatif dan subordinatif dalam berkomunikasi.

Alwi (2003) menyatakan bahwa berdasarkan bentuk sintaksisnya, kalimat dibedakan menjadi; (1) kalimat deklaratif atau berita; (2) kalimat imperatif atau perintah; (3) kalimat interogatif atau tanya; dan (4) kalimat eksklamatif. Kalimat deklaratif adalah kalimat pernyataan yang ditujukan kepada orang lain dengan harapan orang tersebut akan menanggapinya dengan respon yang terlihat dari pandangan mata, mimik, dan kadang disertai dengan anggukan kepala atau ucapan ya (Tarmini, 
2013). Kalimat imperatif merupakan kalimat yang perintah, suruhan, dan permintaan yang meminta mitra tutur melakukan sesuai dengan keinginan penutur. Kalimat imperatif ini dapat berupa kalimat perintah, kalimat himbauan, dan kalimat larangan. (Alwi, 2003;); (Manaf, 2010); (Rahardi, 2005); (Tarmini, 2013). Kalimat interogatif merupakan kalimat tanya yang bergantung dengan jenis jawaban yang dikehendaki atau diharapkan. Ada dua tipe jawaban. Pertama, jawaban yang menghendaki ya atau tidak. Kedua, jawaban yang menghendaki pemaparan berupa informasi yang ditanyakan (Tarmini, 2013). Kalimat eksklamatif merupakan kalimat yang menyatakan kekaguman atau takjub terhadap suatu hal (Alwi, 2003)

Penelitian ini diharapkan dapat bermanfaat secara teoritis dan praktis. Secara teoritis dapat bermanfaat untuk menambah ilmu pengetahuan mengenai pemerolehan bahasa anak usia 3 tahun. Penelitian ini juga dapat bermanfaat bagi orang tua untuk bisa memahami apa yang diucapkan oleh anak mereka. Jika orang tua bisa memahami apa yang diucapkan oleh anak, maka anak akan menjadi senang. Komunikasi akan terjalin baik antara orang tua dan anak. Anak akan merasakan kedekatan batin dengan orangtua. Hal tersebut akan membantu psikologi anak tumbuh menjadi lebih baik.

\section{METODOLOGI}

Metode penelitian yang digunakan dalam penelitian ini adalah metode deskriptif dengan pendekatan kualitatif. Metode deskriptif adalah metode yang meneliti suatu kelompok manusia, suatu subjek, atau pemikiran pada masa sekarang (Nazir, 2011) Metode deskriptif ini digunakan untuk menggambarkan hasil dari pengumpulan data yang telah dilakukan oleh peneliti, melalui wawancara (orang tua, anak) dan observasi secara langsung tentang ujaran yang diucapkan oleh subjek penelitian. Metode deskriptif dipilih oleh peneliti karena metode ini dapat memberikan gambaran secermat mungkin mengenai individu, keadaan, bahasa, gejala, atau kelompok,

Penelitian ini dilakukan dengan cara mengamati secara langsung anak yang menjadi subjek penelitian. Penelitian ini menggunakan teknik simak libat cakap. Peneliti menyimak kata-kata yang bisa diucapkan oleh anak. Peneliti juga ikut berinteraksi dan mendorong subjek penelitian untuk mengucapkan kata-kata. Data dikumpulkan dengan cara mengamati dan memahami bahasa yang diujarkan oleh subjek penelitian. Peneliti mencatat ujaran yang diujarkan oleh subjek penelitian. Penelitian ini dilakukan selama 3 minggu.

Tahap analisis data dalam penelitian ini terdiri atas tiga tahap, yaitu sebagai berikut. Pertama, reduksi. Reduksi dilakukan dengan empat cara, yaitu a. melakukan proses transkripsi data tuturan ke dalam bentuk tulisan; b. data yang telah ditranskripsikan kemudian diidentifikasi; c. melakukan proses pengklasifikasian; $d$. melakukan pemaknaan terhadap data yang sebelumnya sudah diklasifikasikan. Kedua, tahap penyajian. Pada tahap penyajian ini, data yang telah diklasifikasikan disajikan dalam bentuk tabel. Ketiga, tahap penarikan kesimpulan. Dalam tahap ketiga ini, dilakukan proses verifikasi ulang terhadap data awal yang sudah dikumpulkan (Miles dan Huberman, 2014).

\section{HASIL DAN PEMBAHASAN}

Subjek dalam penelitian ini adalah Muhamad Fattan. Subjek penelitian berusia 3 tahun. Subjek penelitian tinggal di Siteba kecamatan Nanggalo, kota Padang. Subjek penelitian ini merupakan anak pertama. Subjek penelitian merupakan tetangga 
peneliti sehingga mempermudah peneliti untuk mengumpulkan data. Bahasa pertama subjek penelitian adalah bahasa Indonesia. Dalam setiap peristiwa tutur yang diperlihatkan, terdapat singkatan $\mathrm{P}$ dan $\mathrm{A}$ yang digunakan. $\mathrm{P}$ adalah singkatan untuk peneliti dan A adalah singkatan untuk Attan (subjek penelitian).

\section{Pemerolehan dalam Tatatran Fonologi}

Dalam analisis fonologi, peneliti mentranskripkan data dalam bentuk fonetis dan teks. Hasil analisis fonologis dapat dilihat dalam pembahasan di bawah ini.

\section{Peristiwa Tutur 1}

A: Ami, Attan main cepeda ya.

P: Ami, Attan main sepedanya sama iya.

A: kak ya, ayo main cepeda.

P: iya Attan, tunggu kakak. Di mana kita main sepedanya?

A: di lual aja.

P: ayo Tan, Attan jangan ngebut ya bawa sepedanya.

A: Attan balap kak.

P: hati-hati tan. Habis main sepeda kita duduk di teras ya,

A: kak ya, ayo duduk cini. Tutup pintu pagal.

P: ya dek. Ayo.

Pada peristiwa tutur 1 di atas, terdapat bunyi bahasa yang mengalami perubahan fonem. Ada satuan fonem yang lesap seperti pada kata sepeda, fonem /s/ berubah menjadi fonem /c/. Selain itu, untuk fonem /r/ berubah menjadi fonem /l/. Hal ini terjadi karena anak berusia 3 tahun belum bisa mengujarkan fonem /r/ dan /s/ dengan benar. Hal ini juga ditemukan dalam penelitian yang dilakukan oleh Wulandari (Wulandari, 2018) yang menemukan bahwa anak usia 3 tahun mengalami perubahan bunyi /r/ berubah menjadi /l/, /s/ diucapkan menjadi /c/. Hal ini sesuai dengan pendapat Jacobson (Chaer, 2007) yang menyatakan bahwa pemerolehan kontras fonemik bersifat universal. Urutan pemerolehan konsonan adalah bilabial-dental (alveolar)palatal-velar. Artinya, apabila anak-anak sudah mampu mengujarkan konsonan frikatif, anak-anak juga sudah mampu mengujarkan bunyi hambat. Apabila anakanak sudah mengujarkan konsonan belakang, itu artinya mereka sudah menguasai konsonan depan.

\section{Pemerolehan dalam Tataran Sintaksis}

Berdasarkan data yang telah dikumpulkan, ditemukan empat jenis kalimat yang diujarkan oleh anak usia 3 tahun yang menjadi subjek dalam penelitian ini. Keempat jenis kalimat tersebut adalah kalimat deklaratif, imperatif, interogatif, dan eksklamatif. Hal ini sesuai dengan pendapat Alwi (Alwi, 2003) yang menyatakan bahwa kalimat dari segi sintaksis ada empat, yaitu kalimat deklaratif, imperatif, interogatif, dan eksklamatif.

\section{Kalimat Deklratif}

\section{Peristiwa tutur 2}

P: Attan lagi ngapain dek?

A: main mobil

P: mobil siapa tu?

A: Attan. Dibeliin Ami.

P: ooo ya dek. Ada berapa mobil Attan ni?

A: dua. Biru sama hijau.

P: bagus mobilnya Attan ya

A: kak ini Tayo. Yang ada lagu nya di tipi. Yang hijau Logi (Rogi)

P: bisa Attan nyanyikan lagunya?

A: bisa. Attan cuka Tayo

P: ayo kita nyanyi bareng dek.

Peneliti dan Attan (subjek penelitian) menyanyikan lagu Tayo bersama.

Berdasarkan peristiwa tutur 2 di atas, kalimat yang termasuk kalimat deklaratif adalah tuturan (1) Attan. Dibelikan Ami; (2) kak ini Tayo. Yang ada lagunya di tipi. Yang hijau Logi (Rogi); dan (3) bisa. Attan 
cuka Tayo. Kalimat tersebut tergolong deklaratif, karena subjek penelitian memberitahu atau menberitakan kepada mitra tutur mengenai benda yang dimilikinya. Subjek penelitian memberitahuk kalau dia mempunyai dua buah mobil seperti yang ada di film kartun dan dia bisa menyanyikan lagunya. Kalimat tersebut menunjukkan bahwa anak bisa mengujarkan kalimat deklaratif dengan baik karena mempunyai pengetahuan tentang apa yang ditanyakan oleh mitra tutur.

Dalam penelitian ini, kalimat yang paling banyak diucapkan oleh subjek penelitian adalah kalimat deklaratif. Hal ini sesuai dengan hasil penelitian yang dilakukan oleh Nursalam (Nursalam \& Nurhikmah, 2018) dan Yuniarsih (Yuniarsih, 2013). Anak usia 3 tahun sudah bisa mengucapkan kalimat deklaratif, interogatif, imperatif, dan ekslamasif. Kalimat yang paling sering diucapkan anak adalah deklaratif dan paling sedikit diucapkan adalah ekslamasif. Hal ini disebabkan oleh anak lebih sering mengucapkan apa yang dia alami dan dirasakan. Hal yang sama juga didapatkan dalam penelitian ini. Setiap kali bertemu dengan peneliti, subjek penelitian lebih banyak memberitahu apa yang dia rasakan, pengalaman yang dialami, dan mainan apa saja yang dia miliki.

\section{Kalimat Imperatif}

\section{Peristiwa Tutur 3}

A: kak jajana di situ aja

P: Mau jajan apa Attan?

A: kue, cokelat

P: iya, ayuk

A: Kakak cepat lah. Pulang kita lagi yuk.

P: tunggu kakak bayar dulu belanjanya

A: kita makan di telas ya, yuk kak

P: ya, ayuk. Bilang apa sama ibuk yang jualan?

A: maacih buk.
Berdasarkan peristiwa tutur 3 di atas, kalimat yang termasuk kalimat imperatif adalah tuturan (1) kakak jajana di situ aja ; (2) kakak cepatlah. Pulang kita lagi yuk; dan (3) kita makan di telas ya, yuk kak. Kalimat (1), (2), dan (3) tergolong kalimat imperatif, karena subjek penelitian menyuruh atau meminta mitra tutur untuk melakukan apa yang diinginkan. Kalimat tersebut diujarkan agar mitra tutur menuruti permintaan subjek penelitian untuk belanja di sebuah warung dan makan diteras.

Dalam penelitian ini, kalimat imperatif ini termasuk kalimat yang jarang diucapkan oleh subjek penelitian. Subjek penelitian hanya sesekali menggunakan kalimat imperatif ketika menemukan hal yang ingin minta orang lain untuk dilakukan. Subjek penelitian termasuk anak yang baik dan penurut. Hal ini sesuai dengan hasil penelitian yang dilakukan oleh Nursalam (Nursalam \& Nurhikmah, 2018) juga menemukan bahwa usia 3,6 tahun sudah bisa mengucapkan kalimat deklaratif, interogatif, dan imperatif.

\section{Kalimat Interogatif}

\section{Peristiwa Tutur 4}

A: uwoo. Mana kak ya wo?

U: kak ya dalam kamar. Masuklah

A: kak ya, pain (lagi ngapain)?

$\mathrm{P}$ : nonton

A: nonton apa kak ya?

P: nonton laptop

A: apa kak ya nonton?

P: nonton film

A: pilm apa kak ya?

P: film dek.

A: kak ya main kita kak ya

P: mau main apa Attan?

A: main cepeda kelual. Ayo kak ya

P: ndak ah

A: cepatlah kak ya

P: ya

A: kak ya tunggu sini, Attan mbil cepeda. P: ya 
Berdasarkan peristiwa tutur 4 di atas, kalimat yang termasuk kalimat interogatif adalah tuturan (1) uwoo. Mana kak ya wo?; (2) kak ya, pain (lagi ngapain)?; (3) apa kak ya nonton?; dan (4) pilm apa kak ya? Kalimat tersebut tergolong interogatif, karena kalimat (2), (3), dan (4) yang diujarkan subjek penelitian menanyakan sesuatu dan meminta mitra tutur untuk menjawab pertanyaan yang diberikan. Kalimat (1) yang diujarakan oleh subjek penelitian menanyakan tempat kepada mitra tutur. Kalimat tersebut diujarkan agar mitra tutur menjawab pertanyaan yang diajukan oleh subjek penelitian.

Dalam penelitian ini, kalimat interogatif ini termasuk kalimat nomor dua yang sering diucapkan oleh subjek penelitian.Subjek penelitian termasuk anak yang ingin tahu terhadap hal yang belum diketahui. Hal ini sesuai dengan hasil penelitian yang dilakukan oleh Nursalam (Nursalam \& Nurhikmah, 2018) juga menemukan bahwa usia 3,6 tahun sudah bisa mengucapkan kalimat deklaratif, interogatif, dan imperatif.

\section{Kalimat Eksklamatif}

\section{Peristiwa Tutur 5}

P: Attan, dari mana Attan dek? Kok g kelihatan Attan dari tadi dek?

A: Attan pelgi

P: Pergi ke mana Attan tadi dek?

A: taplau

P: Sini lah Attan dek, kakak mau dengar cerita Attan. Sama siapa Attan pergi tadi dek?

A: Ami, Abi

P: Ngapain aja Attan di sana tadi dek?

A: Attan tadi lihat ombak besal kak

P: iya?? Ndak takut Attan dek?

A: Attan belani kak

P: trus ngapain lagi Attan

A: Attan naik mobil-mobil kak. Seluu. Ngeeng ngeng

P: Habis tu ngapain Attan lagi dek?

A: Attan main pasil kak
P: habis tu dek?

A: ndak ada. Pulang lagi

P: besok ni ajak kakak pergi ya dek..

A: ya. Nanti bilang Ami

Berdasarkan peristiwa tutur 5 di atas, kalimat yang termasuk kalimat eksklamatif adalah tuturan (1) Attan tadi lihat ombak besal kak; dan (2) Attan naik mobil-mobil kak. Seluu. Ngeeng ngeng Kalimat tersebut tergolong eksklamatif, karena kalimat (1) dan (2) yang diujarkan subjek penelitian menyatakan kekaguman atau kalimat yang menunjukkan perasaan penutur. Kalimat tersebut diujarkan oleh subjek penelitian untuk menyatakan kekagumannya ketika melihat ombak di pantai. Subjek penelitian juga menyatakan pengalaman seru yang dialaminya.

Dalam penelitian ini, kalimat eksklamatif ini termasuk kalimat yang jarang diucapkan oleh subjek penelitian. Subjek penelitian hanya sesekali mengujarkan kalimat eksklamatif ketika menemukan hal yang membuat subjek penelitian kagum atau mengalami kejadian yang menyenangkan dan seru. Hal ini sesuai dengan hasil penelitian yang dilakukan oleh Nursalam (Nursalam \& Nurhikmah, 2018) juga menemukan bahwa usia 3,6 tahun sudah bisa mengucapkan kalimat deklaratif, interogatif, dan imperatif.

\section{Pemerolehan dalam Tataran Semantik}

Hasil penelitian menunjukkan bahwa dalam menentukan makna kata, anak-anak lebih mudah menentukan makna kata yang pernah dilihat dan dekat dengan anak. Hal ini sesuai dengan pendapat Darjowidjojo (Dardjowidjojo, 2000) yang menyatakan bahwa kata-kata yang konkret lebih mudah daripada yang abstrak, karena lebih mudah dan lebih cepat diperoleh. 


\section{Peristiwa Tutur 6}

P: eh si attan, sudah ganteng. Mau kemana Attan?

A: cekolah

P: sekolah si Attan, dimana Attan sekolah dek?

A: Paud halapan bangca

P: pinter Attan ya. Di sekolah nanti Attan ngapain?

A: belajal

P: wih, rajin-rajin belajarnya ya dek.

A: kak ya, Attan bisa hitung

P: wih, hebat Attan, coba berhitung dek

A: berhitung sampai sepuluh.

P: wiih,, tepuk tangan.. Pinter Attan ya dek

A: yeyeyeyye. Dadah kak ya

P: dadah Attan

Berdasarkan peristiwa tutur 6 , dapat dilihat bahwa anak menguasai kata yang dekat dengan lingkungannya. Kata sekolah, belajar, dan berhitung merupakan kata yang dikuasai oleh anak karena dekat dan dialami oleh anak. Sebelumnya, jika anak tidak masuk dalam fase sekolah, anak tidak akan memahami makna kata sekolah, belajar, dan berhitung. Anak juga lebih banyak menggunakan makna denotatif. Makna denotatif merupakan makna asli, asal, atau sebenarnya yang dimiliki oleh leksem (Chaer, 2007). Hal ini juga ditemukan dalam penelitian yang dilakukan oleh Wulandari (Wulandari, 2018) yang menemukan bahwa anak yang berumur 3-5 tahun banyak menggunakan makna denotatif pada jawaban yang dilontarkan sedangkan pada nyanyian bermakna konotati, walaupun ada beberapa jawaban yang mengandung makna konotatif.

\section{KESIMPULAN}

Berdasarkan hasil penelitian, dapat disimpulkan tiga hal dalam pemerolehan bahasa anak usia 3 tahun sebagai berikut. Pertama, pada tataran fonologi didapatkan hasil bahwa anak usia 3 tahun masih belum bisa mengujarkan fonem /r/ dan /s/ dengan benar. Anak usia 3 tahun mengujarkan fonem /r/ menjadi /l/ dan fonem /s/ menjadi /c/. Kedua, pada tataran sintaksis didapatkan hasil bahwa anak usia 3 tahun sudah mampu mengujarkan empat jenis kalimat, yaitu kalimat deklaratif, interogatif, imperatif, dan eksklamatif. Kalimat yang paling sering diujarkan adalah kalimat deklaratif. Ketiga, pada tataran semantik semua ujaran anak mengandung makna denotatif.

\section{UCAPAN TERIMA KASIH}

Penulis menyampaikan ucapan terima kasih kepada orang tua subjek yang telah memberi persetujuan dan membantu peneliti selama proses pengumpulan data. Penulis juga mengucapkan terima kasih kepada pembimbing yang sudah membantu peneliti dalam menyempurnakan hasil penelitian ini. Ucapan terima kasih juga disampaikan kepada tim editor Jurnal Obsesi yang telah memberikan saran, kritik, dan rekomendasi untuk perbaikan artikel ini.

\section{DAFTAR PUSTAKA}

Alwi. (2003). Tata bahasa baku bahasa Indonesia. Jakarta: Balai Pustaka.

Arsanti Meilan. (2014). Pemerolehan bahasa pada anak (kajian psikolinguistik). Jurnal PBSI, 3(2).

Chaer. (2007). Linguistik umum. Jakarta: Rineka Cipta.

Dardjowidjojo. (2000). Echa: kisah pemerolehan bahasa anak Indonesia. Jakarta: Grasindo.

Fauziddin. (2018). Useful of clap hand games for optimalize cognitive aspects in early childhood. Jurnal Obsesi, 2(2).

Manaf. (2010). Sintaksis: teori dan terapannya dalam bahasa Indonesia. Padang: Sukabina Press. 
Manurung, R. (2014). Pemerolehan bahasa pada anak usia 4-5 tahun dengan stimulasi games edukasi. Ranah, 3(1).

Mayasari. (2018). Publikasi bentuk fungsi dan kategori sintaksis tuturan masyarakat Manduro sebagai pendukung perkembangan bahasa anak usia dini. Jurnal Obsesi, 2(1).

Miles dan Huberman. (2014). Analisis data kualitatif: buku sumber tentang metode-metode baru (terjemahan Tjetjep Rohendi Rohidi). Jakarta: UI Press.

Mushaitir. (2016). Pemerolehan sintaksis (B1) bahasa Sasak pada anak usia 4-6 tahun di Lombok Timur melalui permainan tradisional. Jurnal Pendidikan Bahasa Dan Sastra, 16(1).

Nazir. (2011). Metode penelitian. Jakarta: Ghalia Indonesia.

Nurjamiaty. (2015). Pemerolehan bahasa anak usia tiga tahun berdasarkan tontonan kesukaannya ditinjau dari konstruksi semantik. Jurnal Edukasi Kultura, 2(2).

Nursalam \& Nurhikmah. (2018). Representasi kalimat pada tuturan anak usia 3,6 tahun. RETORIKA: Jurnal Bahasa, Sastra, Dan Pengajarannya, 11(2).

Pebriana. (2017). Analisis kemampuan berbahasa dan penanaman moral pada anak usia dini melalui metode mendongeng. Jurnal Obsesi, 1(2).

Rahardi. (2005). Pragmatik kesantunan imperatif bahasa Indonesia. Jakarta: Erlangga.

Safitri, Y. (2017). Faktor-faktor yang berhubungan dengan perkembangan bahasa balita di UPTD kesehatan Baserah tahun 2016. Jurnal Obsesi, 1(1).

Tarmini. (2013). Sintaksis bahasa Indonesia. Bandar Lampung: Universitas Lampung Press.

Wulandari, D. I. (2018). Pemerolehan bahasa Indonesia anak usia 3-5 tahun di PAUD Lestari desa Blimbing kecamatan Paciran kabupaten Lamongan. Lingua Franca: Jurnal Bahasa, Sastra, Dan Pengajarannya, 6(1).

Yogatama, A. (2011). Pemerolehan bahasa pada anak usia 3 tahun ditinjau dari sudut pandang morfosintaksis. LENSA, l(1).

Yuniarsih. (2013). Pemerolehan kalimat bahasa Indonesia pada anak usia 3;04;0 tahun (studi kasus pada Muhamad Ahsan Hafiz). Jurnal Pendidikan Bahasa Dan Seni, 1(2). 